\title{
Solid-state NMR applied to photosynthetic light-harvesting complexes
}

\author{
Anjali Pandit • Huub J. M. de Groot
}

Received: 13 June 2011 / Accepted: 12 July 2011 / Published online: 13 August 2011

(C) The Author(s) 2011. This article is published with open access at Springerlink.com

\begin{abstract}
This short review describes how solid-state NMR has provided a mechanistic and electronic picture of pigment-protein and pigment-pigment interactions in photosynthetic antenna complexes. NMR results on purple bacterial antenna complexes show how the packing of the protein and the pigments inside the light-harvesting oligomers induces mutual conformational stress. The protein scaffold produces deformation and electrostatic polarization of the $\mathrm{BChl}$ macrocycles and leads to a partial electronic charge transfer between the BChls and their coordinating histidines, which can tune the light-harvesting function. In chlorosome antennae assemblies, the NMR template structure reveals how the chromophores can direct their self-assembly into higher macrostructures which, in turn, tune the light-harvesting properties of the individual molecules by controlling their disorder, structural deformation, and electronic polarization without the need for a protein scaffold. These results pave the way for addressing the next challenge, which is to resolve the functional conformational dynamics of the $l h c$ antennae of oxygenic species that allows them to switch between light-emitting and light-energy dissipating states.
\end{abstract}

Keywords Conformational strain - Electronic structures . Chlorosome $\cdot$ Nonphotochemical quenching

\footnotetext{
A. Pandit $(\bowtie)$

Faculty of Sciences, VU University Amsterdam, De Boelelaan 1081, 1081 HV Amsterdam, The Netherlands

e-mail: a.pandit@vu.nl
}

H. J. M. de Groot $(\bowtie)$

Leiden Institute of Chemistry, Leiden University, P.O. Box 9502, 2300 RA Leiden, The Netherlands e-mail: ssnmr@lic.leidenuniv.nl

\section{Introduction}

Natural photosynthesis achieves the conversion of solar energy with a remarkably small set of cofactors. Photosynthetic proteins use (bacterio)chlorophylls (BChls) and carotenoids (Car) both for light-harvesting and charge separation, implying that the functional programming of the pigment chromophores is encoded in their conformation, local environment, and dynamics and is not due to their chemical structure per se. While the architecture of the photosynthetic reaction centers that leads to directional electron transfer is common to all photosynthetic organisms, there is much to be learned about the structurefunction relations from the variability in photosynthetic antenna systems, as evolution has led to fundamentally different architectures for harvesting the light, depending on the variability of environmental sun light conditions. One intriguing puzzle that is currently attracting widespread attention is the molecular basis underlying the photophysical mechanism of nonphotochemical quenching (NPQ), a photoprotective switching mechanism that protects oxygenic species at high sun light conditions while optimally photosynthesizing at low light intensities.

During the past three decades, many structures of photosynthetic membrane proteins have been resolved at high resolution by crystallography, but the details of the structure-function interactions and how cofactors are programmed for their function remain to be elucidated. Solidstate NMR may not outperform crystallography for resolving membrane protein structures, but the technique has compelling advantages when it comes to resolving atomic details of pigment-protein interactions in a flexible protein environment. Better understanding of the structurefunction motifs across antenna complexes and photosynthetic species in an evolutionary context will provide 
knowledge on common denominators of functional mechanisms in natural photosynthetic systems. This will guide the design of novel artificial constructs in which dye molecules are preprogrammed in the ground state by engineering of their scaffolding environment to perform the different tasks of light harvesting, charge separation, and photoprotection (de Groot 2012).

In this short review, we illustrate how solid-state NMR has contributed to a mechanistic picture for the functionalization of the electronic structure of photosynthetic antenna complexes. In addition, we will present an outlook on the application of NMR to light-harvesting antennae of oxygenic organisms, which may enhance our understanding of the molecular mechanisms of NPQ.

Preparation of biological samples for solid-state NMR

In NMR, the signals from nuclear spins are characterized by a parameter called the chemical shift, reflecting the variation of the induced magnetic field relative to the applied magnetic field. The dispersion of NMR frequencies is due to the diamagnetic susceptibility of the electrons in their molecular orbitals, i.e. the magnetic field at the nucleus is reduced by the electronic shielding from the surrounding electrons. The chemical shifts provide atomic selectivity for well-ordered systems and are highly sensitive to the local environment. In contrast to X-ray diffraction techniques that require long-range crystalline order, solid-state NMR can be applied to ordered systems without translation symmetry, including membrane proteins in a detergent shell or a lipid membrane (Renault et al. 2010; Alia et al. 2009; McDermott 2009).

Magnetic resonance occurs only for nuclei with a net nuclear spin and magnetic moment from an uneven number of nucleons. Commonly studied isotopes in natural systems are the spin $1 / 2$ nuclei ${ }^{1} \mathrm{H},{ }^{13} \mathrm{C},{ }^{15} \mathrm{~N}$, and ${ }^{31} \mathrm{P}$. In the solidstate, the $T_{2}$ spin-spin relaxation time is short due do restricted motions, resulting in broad lines. With Magic Angle Spinning (MAS) and high power decoupling the signal overlap can be reduced. Since the ${ }^{1} \mathrm{H}$ NMR chemical shifts fall into a narrow range, indirect detection via heteronuclear coupling with e.g. ${ }^{13} \mathrm{C}$ or ${ }^{15} \mathrm{~N}$ atoms is used to resolve the ${ }^{1} \mathrm{H}$ response. Since the nuclear spin species ${ }^{13} \mathrm{C}$ and ${ }^{15} \mathrm{~N}$ have low natural abundance, sample enrichment with additional isotopes is generally required. For biological samples, these have to be incorporated biosynthetically, for instance by using recombinant proteins that are over-expressed in cell cultures grown on isotope-rich media. Antenna apo-proteins can be expressed in E. coli and re-assembled with their chromophores into functional complexes, but these reconstituted proteins are not easily produced in the milligram quantities required for NMR in the solid state. The $\alpha$ polypeptide of a purple bacterial antenna complex was also successfully expressed in a cellfree in vitro expression system and reconstituted with pigments afterward (Shimada et al. 2004). The advantage of cell-free systems is that isotope-labeled amino acids can be added directly to the synthesis reaction, without losses in the metabolic pathways. In addition, chromophores, membrane lipids, or detergent molecules can be added during the protein synthesis reaction to stimulate protein folding in vitro. For photosynthetic proteins, this could eventually lead to synthesis and folding in one step, with possibilities for selective pigment or amino acid labeling. The first trial of this approach was recently reported for the major light-harvesting complex of Arabidopsis thaliana, of which the $l h c b l$ apoprotein was expressed in a cell-free system in the presence of pigments or lipid nanodisc membranes (Pandit et al. 2011a). As an alternative for over-expression, photosynthetic organisms are grown on isotope-rich minimal media. Labeling experiments included growing of Chlamydomonas green algae cells on ${ }^{13} \mathrm{C}$-enriched Na-acetate (Pandit et al. 2011b), ${ }^{15} \mathrm{~N}$ labeling of spinach (Diller et al. 2007), and growing of Rps. acidophila purple bacteria on ${ }^{13} \mathrm{C}-{ }^{15} \mathrm{~N}$-labeled succinate medium or by using media enriched with ${ }^{13} \mathrm{C}-{ }^{15} \mathrm{~N}$-labeled algal amino acids (van Gammeren et al. 2004). Intrinsic labeling of (bacterio)chlorophylls was performed in purple and cyanobacteria through addition of isotope-labeled aminolevulinic acid (Ala), a precursor of (B)Chl (Janssen et al. 2010; Daviso et al. 2009).

The light-harvesting complex 2 as an NMR model; the protein

By controlled growth of purple bacteria in the presence of $\left[1,2,3,4-{ }^{13} \mathrm{C}\right]$-succinic acid, $\left[1,4-{ }^{13} \mathrm{C}\right]$-succinic acid, $\left[2,3-{ }^{13} \mathrm{C}\right]$-succinic acid, or a mixture of uniformly labeled amino acids, a sequence-specific assignment was obtained for the $\alpha$ - and $\beta$-polypeptides that build up the light-harvesting 2 complex of Rhodopseudomonas acidophila (LH2) (van Gammeren et al. 2005b; Neal et al. 2006). This is the only photosynthetic antenna complex of which an almost complete sequence-specific assignment has been accomplished. For many globular proteins in solution and for some membrane-bound proteins, a sequence-specific assignment enables to predict its secondary structure, since the backbone $\mathrm{C}_{\alpha}, \mathrm{C}_{\beta}$, and $\mathrm{CO}$ chemical shifts cover different ranges for $\alpha$-helical and $\beta$-sheet proteins, and these ranges are also different from the $\mathrm{C}_{\alpha}, \mathrm{C}_{\beta}$, and $\mathrm{CO}$ dispersion for random coils (Neal et al. 2006; Cornilescu et al. 1999). The differences between the experimental backbone chemical shifts and their random coil values are called the secondary shifts and in general they correlate with the backbone torsion angles $\Psi, \Phi$, and $\omega$. The LH2 secondary shifts, however, showed several mismatches pointing to a 
$\beta$-sheet arrangement within the $\alpha$-helical stretches in the crystal structure (Pandit et al. 2010b). The irregularities were attributed to localized structural distortions or electronic perturbations, induced by the rigid packing of the pigment-protein complex into a ring-shaped oligomer. Figure 1 shows the mapping of the NMR chemical shift perturbations on the available crystal structure to visualize where local points of conformational strain may occur along the protein backbone. This illustrates how the NMR data reveal information that is complementary to crystallographic data, and this provides synergy, rather than two separate methods for structure determination.

The BChl-coordinating histidines (His) of the LH2 acidophila complex were studied extensively by selective ${ }^{13} \mathrm{C}$ and ${ }^{15} \mathrm{~N}$ labeling. The two neutral His that coordinate the BChls appeared to have the NMR signatures of a double-protonated, i.e. positively charged His (Alia et al. 2001, 2004). This was explained by a charge transfer in the ground state between the His and their coordinating $\mathrm{BChl}$, resulting in a partial positive charge on the His imidazoles. In density functional theory (DFT) modeling, the effect would disappear if the BChl-His geometry was optimized beforehand, but was clearly present when the coordinates were taken directly from the X-ray structure (Wawrzyniak et al. 2008). Running a geometry optimization would increase the distance between the His and the $\mathrm{BChl}$ from 2.12 to $2.31 \AA$. One could argue that this moderate change falls within the error of the X-ray spatial resolution, and indeed the sensitivity of the NMR chemical shifts to electronic effects, which might be induced by small spatial re-arrangements, exceeds the resolution of the X-ray crystallographic structures. The LH2 His model explained the electronic effects of charge transfer by mechanical stress, induced by the protein conformational constraints in the LH2 oligomer packing. It was speculated that the His-BChl charge transfer could have an effect on the lightharvesting properties. A more clear example how a coordinating His may control the chromophore function was found for the special pair of photosystem II. Here, the inverted electronic charge of the $\mathrm{Chl}$ nitrogens in the special pair was explained by a hinge model, in which the coordinating His imidazole ring hangs over the Chl macrocycle, altering its electronic structure in the ground state and its oxidation state compared to PSI (Diller et al. 2007).

The light-harvesting complex 2 as an NMR model; the BChl pigments

In addition to the protein chemical shifts, NMR assignments were obtained for the BChl-conjugated macrocycles of the three types of BChl in LH2: the $\alpha$ - and $\beta$-bound BChls that build a ring of $\mathrm{BChl}$ dimers, called the $\mathrm{B} 850$ band, and the so-called B800 BChls that form a ring of monomers (van Gammeren et al. 2005a). To discriminate between the B850

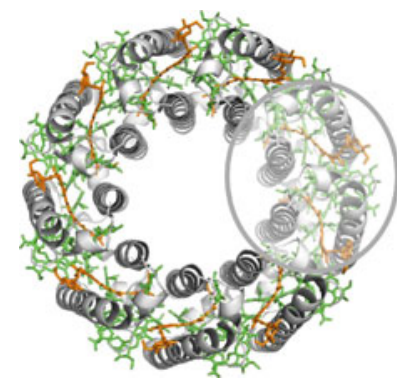

intra-subunit $\mathrm{H}$-bonds

B800 region
van der Waals contacts
Car, BChl (H-bond BChl)

B850 region BChl-coordinating His

inter-subunit $\mathrm{H}$-bonds

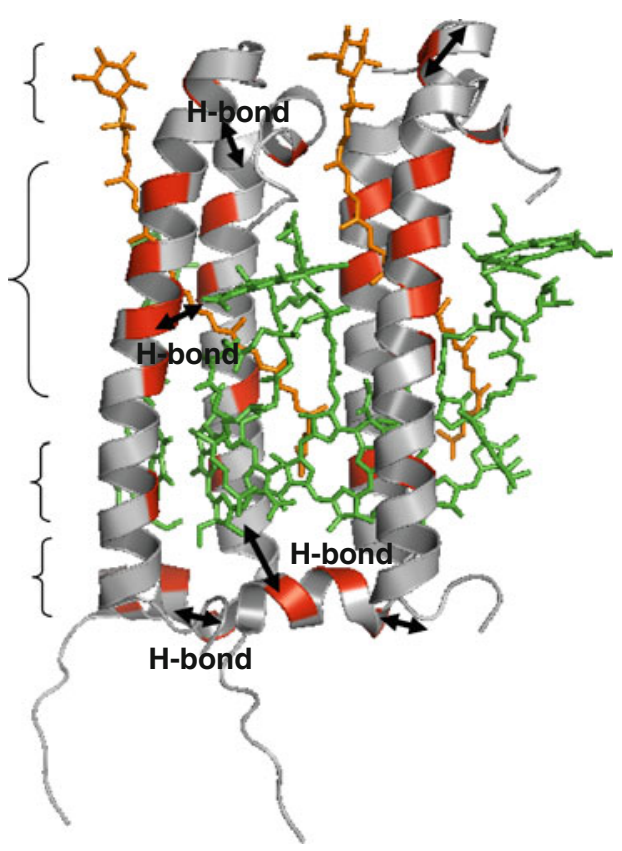

Fig. 1 Chemical shift mapping of the Rps. acidophila LH2 complex. The perturbed secondary shifts are highlighted and correlate with pigmentprotein or protein-protein interactions in the assembly 

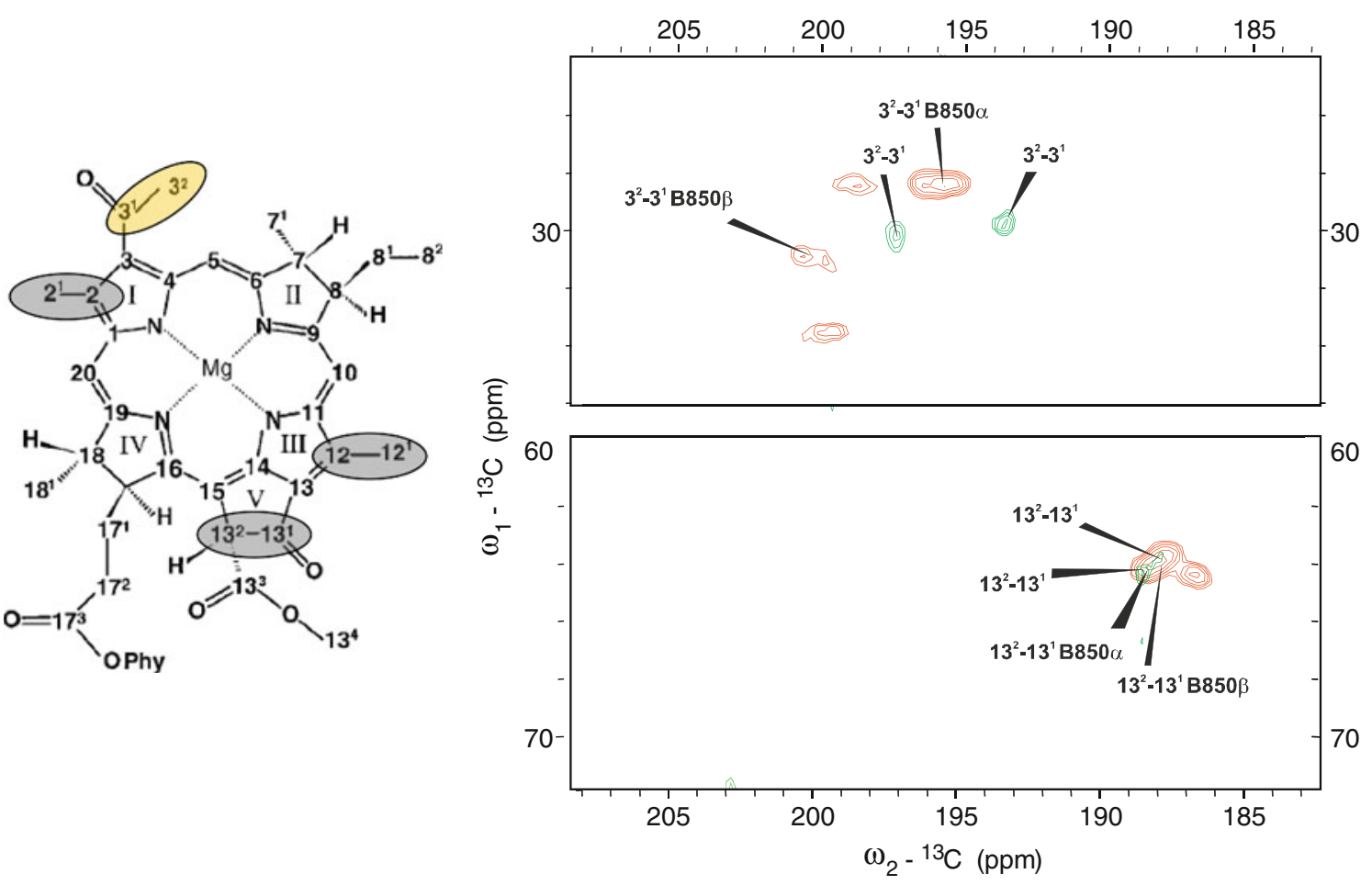

Fig. 2 Comparison of the ground-state electronic structures of Rps. acidophila LH1 and LH2 B850 BChls. Left Side chain atoms with similar values for the LH1 and LH2 BChls are highlighted in gray and

and B800 signals, a sample was prepared from unlabeled LH2 of which the B800 BChls were extracted and substituted with uniformly labeled BChls. The three types of BChls have a distinctive set of chemical shifts, reflecting their conformational structures and variation in the local protein environment. The differences between the NMR signals in the protein-bound $\mathrm{BChls}$ and free $\mathrm{BChl}$ in organic solvent $\Delta \sigma$ determine the electronic structures in the ground state. Recently, the data set was expanded with the BChl assignments of the acidophila LH1 complex, the core antenna that forms a ring-shaped oligomer of dimer $\alpha \beta$ subunits surrounding the photosynthetic reaction center (RC) (Pandit et al. 2010a). Due to their less-ordered oligomer structures, crystallization of the LH1 protein complexes has only resulted in low-resolution structures (Roszak et al. 2003; Karrasch et al. 1995). The LH1 structural inhomogeneity similarly induces broadening of the lines in the NMR spectra and in an earlier study on Rhodospirillum rubrum LH1 $\alpha \beta$ subunits reconstituted with ${ }^{13} \mathrm{C}-{ }^{15} \mathrm{~N}$-labeled BChls, only one set of BChl NMR signals was assigned without distinction between the $\alpha$ - and $\beta$-BChl (Wang et al. 2002). In our recent work, NMR assignment of the two types of LH1 BChls was achieved in intact LH1-RC core complexes, using the LH2 spectra as a "template" for the assignment. Two sets of signals were observed, corresponding with the electronic structures of the $\alpha$ - and the differences are highlighted in yellow. Right ${ }^{13} \mathrm{C}-{ }^{13} \mathrm{C}$ NMR homonuclear correlation spectra of the LH1-RC protein (green), overlaid on the spectrum of LH2 (red) obtained under similar conditions

$\beta$-bound BChls in LH1 that also form a ring of dimers, similar to LH2. By overlay of the LH1 and LH2 2D-NMR spectra, the $\mathrm{BChl}$ ground-state electronic structures of the homologous LH2 and LH1 antenna rings were directly compared, revealing differences and similarities in their conformation or local protein environment with atomic selectivity (Fig. 2). This method circumvents referencing to monomeric $\mathrm{BChl}$ in an organic solvent, of which chemical shift values are biased by the solvent polarity.

The LH1 and LH2 BChl NMR chemical shift patterns on the one hand could not be modeled by the effects of hydrogen bonding, side chain out-of-plane rotation and long-range electrostatic interactions, suggesting that the $\mathrm{BChl}$ electronic structures in the ground state are mainly shaped by macrocycle deformation (Pandit et al. 2010a). Chlorophyll macroaromatic cycles are readily distorted, which makes for a very flexible electronic structure of the porphyrin ring, where the electronic densities follow the distortions imposed upon the structure due to the predominant electron-phonon coupling. The effect of structural deformation of the chromophores, however, was omitted in prediction of the site energies and corresponding excitonic couplings of the pigments inside the major light-harvesting complex II (LHCII) and of the Fenna-Mathews-Olson (FMO) complex, due to uncertainties in the crystal structures used for the calculations that otherwise could lead to 
overestimation of the transition dipoles (Muh et al. 2010; Adolphs et al. 2008). Also, here the NMR data thus complement the crystallographic data and eventually may be combined in a synergistic way for more accurate prediction of pigment site energies. For instance, shifting electron density over the macrocycle allows for changing the direction and magnitude of the electric dipole moment and the polarizability tensor, and the local electronic densities behind such processes can be probed through the NMR chemical shift (He et al. 2001; Wawrzyniak et al. 2008).

The chlorosome antennae

In contrast to the antenna apparatus of all other photosynthetic organisms, the heterogeneous chlorosome antennae of green photosynthetic bacteria contain rod-shaped oligomers of BChl-c/d/e molecules that self aggregate without assistance of a protein. Their structural functional features have been the inspiration for self-assembled artificial antennae (Ganapathy et al. 2009b; Oostergetel et al. 2010; Balaban et al. 2005). The $\pi-\pi$ interactions of overlapping macrocycles from the adjacent $\mathrm{BChls}$ give rise to ringcurrent shifts; an effect in which the electronic ring current of the macrocycles induces a local magnetic field that affects the NMR chemical shifts of the adjacent BChl in the structure with molecular overlap. The magnitudes of the ring-current shifts together with long-range ${ }^{1} \mathrm{H}-{ }^{13} \mathrm{C}$ correlations provide constraints for the packing mode of the BChls in the macrostructures (van Rossum et al. 2002). In conjunction with distance constraints from diffraction techniques and computational modeling, this provided a method to solve a template for the chlorosome self-assembled structure in detail. By constructing a triple mutant, the heterogeneous BChl-c pigment composition of chlorosomes of the green sulfur bacteria Chlorobaculum tepidum was simplified to nearly homogeneous $\mathrm{BChl} d$. Computational integration of solid-state NMR and cryo-electron microscopy revealed a syn-anti stacking mode and led to a structural model of BChls self-assembled into coaxial cylinders to form tubular-shaped elements. (Ganapathy et al. 2009a). The macrostructures are stabilized by $\mathrm{C}=\mathrm{O} \bullet \bullet \mathrm{H}-\mathrm{O} \bullet \bullet \mathrm{Mg}$ interactions between the $3^{1}$ hydroxy group, the 13 carbonyl and the central magnesium, and by $\pi-\pi$ interactions between the tetrapyrrole macrocycles (Fig. 3). Since low-lying CT states are an intrinsic property of higher aggregates of chlorophyll molecules and are likely to mix significantly with the exciton states, the polarizability effects in chlorosome aggregates are strongly enhanced compared to BChl- $c$ monomers. The structural framework can accommodate chemical heterogeneity in the side chains for adaptive optimization of the light-harvesting functionality by optical tuning and broadening. In addition, the BChls form sheets that allow for strong exciton overlap in two dimensions, enabling triplet exciton formation for photo protection.

Outlook: the conformational switch in oxygenic light-harvesting systems

Oxygenic photosynthetic organisms have a built-in photoprotection mechanism, in which under excess light conditions the antenna system switches from a light-harvesting to a light-energy dissipating state, in which the excitedstate energy is safely dissipated as heat. The photophysical mechanism of NPQ involves a change of the pigment configurations, creating an energy dissipation pathway via

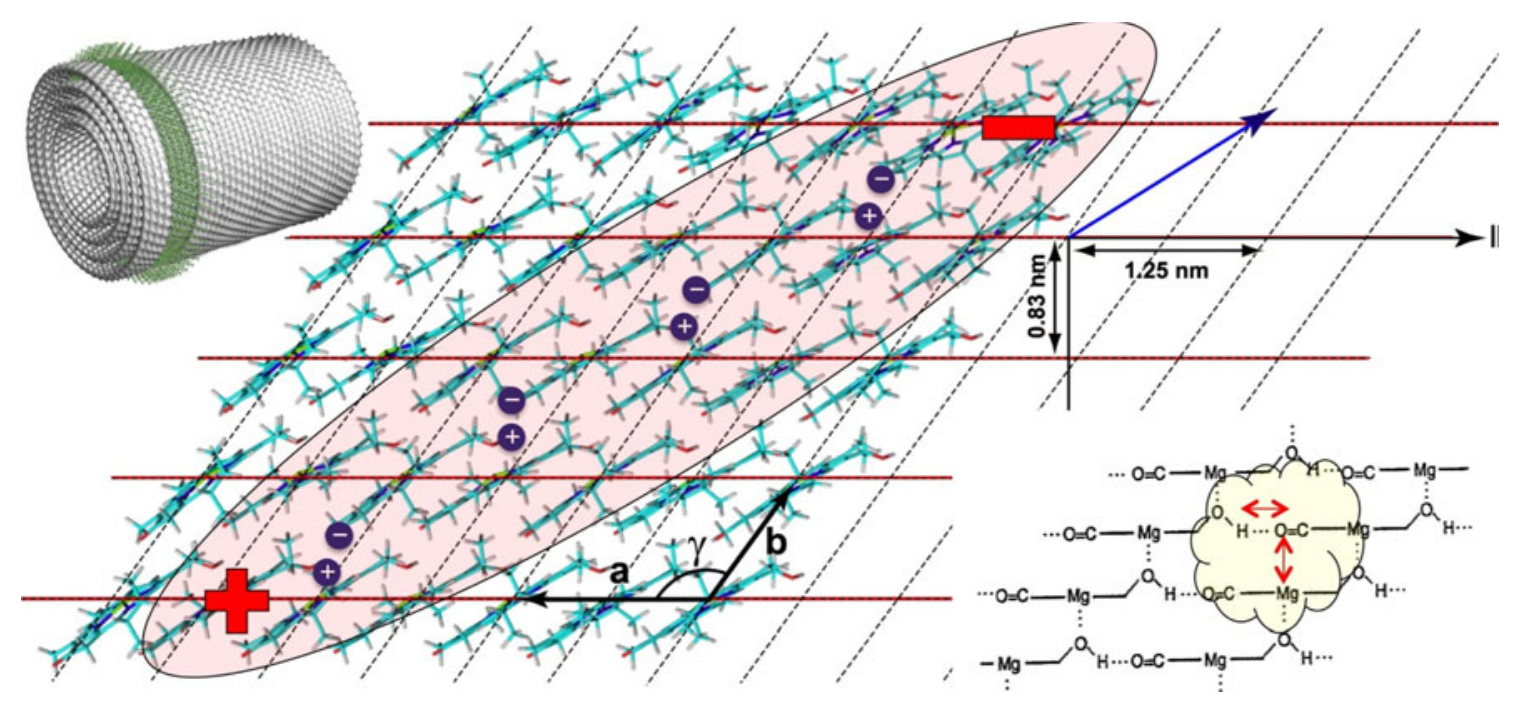

Fig. 3 Chlorosome NMR template structure, illustrating how large polarizability effects are facilitated by the aligned electric dipoles of the individual $\mathrm{BChl}$ molecules 
one of the pigments. The exact mechanism is under much debate and several models have been proposed, based on intra- or intermolecular conformational changes and/or cofactor exchange (Holzwarth et al. 2009; Ruban et al. 2007; Ahn et al. 2008; Standfuss et al. 2005; Holt et al. 2005). In vitro, fluorescence quenching occurs upon aggregation of the LHCII complexes, with spectroscopic signatures similar to the (Wawrzyniak et al. 2008) state in leaves and chloroplasts, suggesting that they underlie very similar photophysical mechanisms. In particular, Resonance Raman shows a twist of the neoxanthin (Neo) carotenoid upon quenching in vivo as well as in vitro (Ruban et al. 2007), demonstrating that conformational changes indeed occur. For the major light-harvesting complex II from plants (LHCII), conformational switching was observed without self-aggregation of LHCII proteins entrapped in gels (Ilioaia et al. 2008) and of LHCII trimer complexes studied by single-molecule fluorescence microscopy (Kruger et al. 2010). This suggests that the individual antenna complexes have a built-in capacity to switch between different functional conformational states, triggered by the protein local environment that can shift the dynamic equilibrium between the light-harvesting and the NPQ states. A shift of a dynamic equilibrium has been observed before with MAS NMR, e.g. for 7-helix membrane proteins in relation to signal transduction, and NMR is a good method to analyze the relation between structure and the triggering of function for such processes (Ratnala et al. 2007; Etzkorn et al. 2007).

Despite the availability of two high-resolution LHCII crystal structures (Standfuss et al. 2005; Liu et al. 2004), the more subtle conformational dynamics related to NPQ remain to be resolved. In the LH2 NMR model it was shown that by using the X-ray structure of LH2, the NMR data could predict different aspects of conformational strain in the form of localized electronic perturbations, on the level of (1) the protein backbone, (2) the selective pigment-coordinating sites, and (3) the protein-bound chromophores. Recently, the first NMR experiments were performed on the LHCII trimer complexes of the green alga Chlamydomonas reinhardtii, which have a high degree of homology with the LHCII complexes of higher plants (Pandit et al. 2011b). The dispersion of the NMR signals is good, and possible conformational changes will be observable already in uniformly isotope-labeled samples. The NMR samples can be prepared in aggregated or detergent-solubilized conditions, modulating the photophysical state of the LHCII in vitro. By selective labeling of amino acids, for instance through the use of Chlamydomonas auxotrophic amino acid-deficient strains, the role of important amino acids in the quenching process can be followed without the need for mutational approaches. In addition, intrinsic Chl labeling is possible through the supply of isotope-labeled Ala to the cells (Janssen et al. 2010). By sparse labeling of chlorophylls, the NMR signals of these pigments can be resolved from the protein background signals, in order to identify the role of different Chls (Schulten et al. 2002). The assignment of the Car pigments will be more difficult, since there is strong overlap between the NMR signals of their polyene chain ${ }^{13} \mathrm{C}$ nuclei. Characterization of the xanthophylls properties by NMR will probably rely on the use of recombinant proteins, where xanthophyll chromophores are substituted by selectively labeled isotopomers (de Groot et al. 1992).

The next challenge is to apply these NMR methods, which have been proven successful for characterization of purple bacterial antennae and of various photosynthetic reaction centers, to the more complex light-harvesting systems of oxygenic photosynthetic organisms, where subtle conformational features may have a functional role in maintaining the integrity of the photosynthetic antenna under high light and drought stress conditions.

Open Access This article is distributed under the terms of the Creative Commons Attribution Noncommercial License which permits any noncommercial use, distribution, and reproduction in any medium, provided the original author(s) and source are credited.

\section{References}

Adolphs J, Muh F, Madjet MEA, Renger T (2008) Calculation of pigment transition energies in the FMO protein. Photosynth Res 95(2-3):197-209. doi:10.1007/s11120-007-9248-z

Ahn TK, Avenson TJ, Ballottari M, Cheng YC, Niyogi KK, Bassi R, Fleming GR (2008) Architecture of a charge-transfer state regulating light harvesting in a plant antenna protein. Science 320(5877):794-797. doi:10.1126/science. 1154800

Alia, Matysik J, Soede-Huijbregts C, Baldus M, Raap J, Lugtenburg J, Gast P, van Gorkom HJ, Hoff AJ, de Groot HJM (2001) Ultrahigh field MAS NMR dipolar correlation spectroscopy of the histidine residues in light-harvesting complex II from photosynthetic bacteria reveals partial internal charge transfer in the B850/His complex. J Am Chem Soc 123 (20):4803-4809. doi:10.1021/ja002591z

Alia Matysik J, de Boer I, Gast P, van Gorkom HJ, de Groot HJM (2004) Heteronuclear 2D (H-1-C-13) MAS NMR resolves the electronic structure of coordinated histidines in light-harvesting complex II: assessment of charge transfer and electronic delocalization effect. J Biomol NMR 28(2):157-164. doi: 10.1023/B:JNMR.0000013842.72291.48

Alia A, Ganapathy S, de Groot HJM (2009) Magic angle spinning (MAS) NMR: a new tool to study the spatial and electronic structure of photosynthetic complexes. Photosynth Res 102(2-3):415-425. doi:10.1007/s11120-009-9478-3

Balaban TS, Linke-Schaetzel M, Bhise AD, Vanthuyne N, Roussel C, Anson CE, Buth G, Eichhofer A, Foster K, Garab G, Gliemann H, Goddard R, Javorfi T, Powell AK, Rosner H, Schimmel T (2005) Structural characterization of artificial self-assembling porphyrins that mimic the natural chlorosomal Bacteriochlorophylls c, d, and e. Chem-Eur J 11(8):2268-2275. doi:10.1002/ chem. 200400664 
Cornilescu G, Delaglio F, Bax A (1999) Protein backbone angle restraints from searching a database for chemical shift and sequence homology. J Biomol NMR 13(3):289-302

Daviso E, Prakash S, Alia A, Gast P, Neugebauer J, Jeschke G, Matysik J (2009) The electronic structure of the primary electron donor of reaction centers of purple bacteria at atomic resolution as observed by photo-CIDNP C-13 NMR. Proc Natl Acad Sci USA 106(52):22281-22286. doi:10.1073/pnas.0908608106

de Groot H (2012) Engineered natural photosynthesis. In: Ginley DS, Cahen D (eds) Fundamentals of materials for energy and environmental sustainability. Cambridge University Press, Cambridge, UK

de Groot HJ, Gebhard R, Van der Hoef I, Hoff AJ, Lugtenburg J, Violette CA, Frank HA (1992) 13C magic angle spinning NMR evidence for a $15,15^{\prime}$-cis configuration of the spheroidene in the Rhodobacter sphaeroides photosynthetic reaction center. Biochemistry 31(49):12446-12450. doi:10.1021/bi00164a021

Diller A, Roy E, Gast P, van Gorkom HJ, de Groot HJM, Glaubitz C, Jeschke G, Matysik J, Alia A (2007) N-15 photochemically induced dynamic nuclear polarization magic-angle spinning NMR analysis of the electron donor of photosystem II. Proc Natl Acad Sci USA 104(31):12767-12771. doi:10.1073/pnas. 0701763104

Etzkorn M, Martell S, Andronesi OC, Seidel K, Engelhard M, Baldus M (2007) Secondary structure, dynamics, and topology of a seven-helix receptor in native membranes, studied by solid-state NMR spectroscopy. Angew Chem Int Ed 46(3):459-462. doi: 10.1002/anie.200602139

Ganapathy S, Oostergetel GT, Wawrzyniak PK, Reus M, Chew AGM, Buda F, Boekema EJ, Bryant DA, Holzwarth AR, de Groot HJM (2009a) Alternating syn-anti bacteriochlorophylls form concentric helical nanotubes in chlorosomes. Proc Natl Acad Sci USA 106(21):8525-8530. doi:10.1073/pnas. 0903534106

Ganapathy S, Sengupta S, Wawrzyniak PK, Huber V, Buda F, Baumeister U, Wurthner F, de Groot HJM (2009b) Zinc chlorins for artificial light-harvesting self-assemble into antiparallel stacks forming a microcrystalline solid-state material. Proc Natl Acad Sci USA 106(28):11472-11477. doi:10.1073/pnas. 0811872106

He Z, Sundström V, Tn Pullerits (2001) Excited states of carotenoid in LH2: an ab initio study. Chem Phys Lett 334(1-3):159-167. doi:10.1016/S0009-2614(00)01338-5

Holt NE, Zigmantas D, Valkunas L, Li XP, Niyogi KK, Fleming GR (2005) Carotenoid cation formation and the regulation of photosynthetic light harvesting. Science 307(5708):433-436. doi:10.1126/science. 1105833

Holzwarth AR, Miloslavina Y, Nilkens M, Jahns P (2009) Identification of two quenching sites active in the regulation of photosynthetic light-harvesting studied by time-resolved fluorescence. Chem Phys Lett 483(4-6):262-267. doi:10.1016/ j.cplett.2009.10.085

Ilioaia C, Johnson MP, Horton P, Ruban AV (2008) Induction of efficient energy dissipation in the isolated light-harvesting complex of photosystem II in the absence of protein aggregation. J Biol Chem 283(43):29505-29512. doi:10.1074/jbc. M802438200

Janssen GJ, Daviso E, van Son M, de Groot HJM, Alia A, Matysik J (2010) Observation of the solid-state photo-CIDNP effect in entire cells of cyanobacteria Synechocystis. Photosynth Res 104(2-3):275-282. doi:10.1007/s11120-009-9508-1

Karrasch S, Bullough PA, Ghosh R (1995) The 8.5-angstrom projection map of the light-harvesting complex-I from rhodospirillum-rubrum reveals a ring composed of 16 subunits. EMBO J 14(4):631-638
Kruger TPJ, Novoderezhkin VI, Ilioaia C, van Grondelle R (2010) Fluorescence spectral dynamics of single LHCII trimers. Biophys J 98(12):3093-3101. doi:10.1016/j.bpj.2010.03.028

Liu ZF, Yan HC, Wang KB, Kuang TY, Zhang JP, Gui LL, An XM, Chang WR (2004) Crystal structure of spinach major lightharvesting complex at 2.72 angstrom resolution. Nature 428(6980):287-292. doi:10.1038/nature02373

McDermott A (2009) Structure and dynamics of membrane proteins by magic angle spinning solid-state NMR. Ann Rev Biophys 38:385-403. doi:10.1146/annurev.biophys.050708.133719

Muh F, Madjet MEA, Renger T (2010) Structure-based identification of energy sinks in plant light-harvesting complex II. J Phys Chem B 114(42):13517-13535. doi:10.1021/jp106323e

Neal S, Berjanskii M, Zhang HY, Wishart DS (2006) Accurate prediction of protein torsion angles using chemical shifts and sequence homology. Magn Reson Chem 44:S158-S167. doi: $10.1002 / \mathrm{mrc} .1832$

Oostergetel GT, van Amerongen H, Boekema EJ (2010) The chlorosome: a prototype for efficient light harvesting in photosynthesis. Photosynth Res 104(2-3):245-255. doi:10.1007/s11120-0109533-0

Pandit A, Buda F, van Gammeren AJ, Ganapathy S, de Groot HJM (2010a) Selective chemical shift assignment of Bacteriochlorophyll a in uniformly [C-13-N-15]-labeled light-harvesting 1 complexes by solid-state NMR in ultrahigh magnetic field. J Phys Chem B 114(18):6207-6215. doi:10.1021/jp100688u

Pandit A, Wawrzyniak PK, van Gammeren AJ, Buda F, Ganapathy S, de Groot HJM (2010b) Nuclear magnetic resonance secondary shifts of a light-harvesting 2 complex reveal local backbone perturbations induced by its higher-order interactions. Biochemistry 49(3):478-486. doi:10.1021/bi9016236

Pandit A, de Ruijter M, Brandsma H, Brouwer J, de Groot HJM, de Grip WJ (2011a) Cell-free expression of the lhcbl protein of Arabidopsis thaliana. Proceedings of the 15th international congress of photosynthesis, Beijing, China

Pandit A, Morosinotto T, Reus M, Holzwarth AR, Bassi R, de Groot HJM (2011b) First solid-state NMR analysis of uniformly C-13enriched major light-harvesting complexes from Chlamydomonas reinhardtii and identification of protein and cofactor spin clusters. Biochim Biophys Acta Bioenerg 1807(4):437-443. doi: 10.1016/j.bbabio.2011.01.007

Ratnala VRP, Kiihne SR, Buda F, Leurs R, de Groot HJM, Degrip WJ (2007) Solid-state NMR evidence for a protonation switch in the binding pocket of the $\mathrm{H} 1$ receptor upon binding of the agonist histamine. J Am Chem Soc 129(4):867-872. doi:10.1021/ ja0652262

Renault M, Cukkemane A, Baldus M (2010) Solid-state NMR spectroscopy on complex biomolecules. Angew Chem Int Ed 49(45):8346-8357. doi:10.1002/anie.201002823

Roszak AW, Howard TD, Southall J, Gardiner AT, Law CJ, Isaacs NW, Cogdell RJ (2003) Crystal structure of the RC-LH1 core complex from Rhodopseudomonas palustris. Science 302(5652): 1969-1972. doi:10.1126/science.1088892

Ruban AV, Berera R, Ilioaia C, van Stokkum IHM, Kennis JTM, Pascal AA, van Amerongen $\mathrm{H}$, Robert B, Horton $\mathrm{P}$, van Grondelle R (2007) Identification of a mechanism of photoprotective energy dissipation in higher plants. Nature 450 (7169): 575-578. doi:10.1038/nature06262

Schulten EAM, Matysik J, Alia, Kiihne S, Raap J, Lugtenburg J, Gast P, Hoff AJ, de Groot HJM (2002) (13)C MAS NMR and photoCIDNP reveal a pronounced asymmetry in the electronic ground state of the special pair of Rhodobacter sphaeroides reaction centers. Biochemistry 41 (27):8708-8717

Shimada Y, Wang ZY, Mochizuki Y, Kobayashi M, Nozawa T (2004) Functional expression and characterization of a bacterial light- 
harvesting membrane protein in Escherichia coli and cell-free synthesis systems. Biosci Biotechnol Biochem 68(9):1942-1948 Standfuss R, van Scheltinga ACT, Lamborghini M, Kuhlbrandt W (2005) Mechanisms of photoprotection and nonphotochemical quenching in pea light-harvesting complex at $2.5 \mathrm{~A}$ resolution. EMBO J 24(5):919-928. doi:10.1038/sj.emboj.7600585

van Gammeren AJ, Hulsbergen FB, Hollander JG, de Groot HJM (2004) Biosynthetic site-specific C-13 labeling of the lightharvesting 2 protein complex: a model for solid state NMR structure determination of transmembrane proteins. J Biomol NMR 30(3):267-274. doi:10.1007/s10858-004-3736-7

van Gammeren AJ, Buda F, Hulsbergen FB, Kiihne S, Hollander JG, Egorova-Zachernyuk TA, Fraser NJ, Cogdell RJ, de Groot HJM (2005a) Selective chemical shift assignment of B800 and B850 bacteriochlorophylls in uniformly [C-13, N-15]-labeled lightharvesting complexes by solid-state NMR spectroscopy at ultrahigh magnetic field. J Am Chem Soc 127(9):3213-3219. doi: $10.1021 / \mathrm{ja} 044215 \mathrm{a}$

van Gammeren AJ, Hulsbergen FB, Hollander JG, de Groot HJM (2005b) Residual backbone and side-chain C-13 and N-15 resonance assignments of the intrinsic transmembrane lightharvesting 2 protein complex by solid-state magic angle spinning NMR spectroscopy. J Biomol NMR 31(4):279-293. doi:10. 1007/s10858-005-1604-8

van Rossum BJ, Schulten EAM, Raap J, Oschkinat H, de Groot HJM (2002) A 3-D structural model of solid self-assembled chlorophyll a/ $\mathrm{H}_{2} \mathrm{O}$ from multispin labeling and MAS NMR 2-D dipolar correlation spectroscopy in high magnetic field. J Magn Reson 155(1):1-14. doi:10.1006/jmre.2002.2502

Wang ZY, Muraoka Y, Shimonaga M, Kobayashi M, Nozawa T (2002) Selective detection and assignment of the solution NMR signals of bacteriochlorophyll a in a reconstituted subunit of a light-harvesting complex. J Am Chem Soc 124(6):1072-1078. doi:10.1021/ja0112994

Wawrzyniak PK, Alia A, Schaap RG, Heemskerk MM, de Groot HJM, Buda F (2008) Protein-induced geometric constraints and charge transfer in bacteriochlorophyll-histidine complexes in LH2. Phys Chem Chem Phys 10(46):6971-6978. doi:10.1039/ b810457c 